\title{
The Role of Time Constraints in Athletes' Egocentric Mental Rotation Performance
}

\author{
Tian Feng', Yawei Li', Zhiguang $\mathrm{Ji}^{2}$, Zhongqiu Zhang ${ }^{3}$ \\ 'Physical Education College of Zhengzhou University, Zhengzhou, China \\ ${ }^{2}$ Shanghai University of Medicine \& Health Science, Shanghai, China \\ ${ }^{3}$ China Institute of Sport Science, Beijing, China
}

ABSTRACT

A selective effect of motor expertise on mental rotation is revealed by a high correlation between the performance of sports experts and ability on a mental rotation task. Evidence is shown by studies involving a spatial factor, such as image interference or a movement constraint. Alternatively, the time constraint, as another performance factor, is considered critical in the effect of sport expertise on mental rotation. Three experiments were conducted to examine the role of time constraints in egocentric mental rotation and the stage performance of athletes (divers) and nonathletes. In Experiment 1, an egocentric mental rotation task in an untimed condition was conducted, and reaction times (RTs), error rates (ERs), RTs at $0^{\circ}$, and mental rotation speed were assessed. The results indicated that divers outperformed nonathletes in terms of RT, as well as perceptual and decision stages and rotation stages. Experiments 2 and 3 added a relative time constraint (subtracting $1 / 2$ SD of all the subjects' RT from the M of each group's RT) and an absolute time constraint (subtracting $1 / 2 S D$ of all the subjects' $R T$ from the $M$ of all the subjects' $R T$ ) to the task, respectively. Superior RT and lower ER were observed for the divers in the time constraint condition. Moreover, the results illustrated that divers were faster than nonathletes in both stages when facing time pressure. In general, the present study has, for the first time, confirmed the role of time in the relationship between sports expertise and mental rotation.

egocentric transformations embodied cognition

\section{KEYWORDS}

mental rotation

sport expertise

process stages
Concerning the processes of mental rotation in sports experts, the theory of embodied cognition has been highlighted in numerous studies. This concept suggests that an individual's cognitive ability is influenced by their environmental perception, and thus, that cognitive processes are deeply rooted in the interactions between the body and the environment (Wilson, 2002). It has been shown that in the activities that have considerable spatial reasoning demands, individuals' mental representations of their body is often continuously updated with regard

Corresponding author: Yawei Li, Physical Education College of Zhengzhou University, Zhengzhou, China. E-mail: yaweili@vip.126.com pertise level for some elite athletes (Hoyek, Champely, Collet, Fargier, \& Guillot, 2014; Voyer \& Jansen, 2017). 
to its position or movement. Athletes are asked to manipulate complex mental representations, such that mental rotation abilities could be embodied and benefit the most from these types of activities (Ionta \& Blanke, 2009; Moreau, Clerc, Mansy-Dannay, \& Guerrien, 2012).

In mental rotation, egocentric transformations are those in which an object stays fixed while the observer's point of view rotates in relation to the object or the environment. These kinds of transformations often use the mental body rotation test (MBRT), in which participants are asked to carry out left-right judgements with the human body as a stimulus. Studies concerning MBRT indicated that athletes outperform nonathletes because the task elicits the embodied spatial transformation of the athletes (Kaltner, Riecke, \& Jansen, 2014; Steggemann, Engbert, \& Weigelt, 2011). Moreover, superior performance was found when there was a high correlation between the task and the sport environment, thus revealing a selective effect of motor expertise on mental rotation. For example, Habacha, Molinaro, Tabben, and LejeunePoutrain (2014) conducted the mental rotation task with figures of hands in table tennis players and found faster reaction times (RTs) of the athletes only if the figures were in accordance with their dominant hands. In line with this finding, Heinen, Jeraj, Vinken, and Velentzas (2012) investigated male gymnasts with stimuli that were either congruent or incongruent with their rotation preference and found faster RTs for gymnasts in the congruent condition.

Both theoretical and experimental studies have provided evidence that motor processes play an important role in mental rotation. First, embodied cognition implies that many cognitive processes have a motor component. Additionally, some studies using the MBRT have shown that mental transformation shares the same temporal and kinematic properties with actual body transformations (Parsons, 1987; Shepard \& Metzler, 1971). Kaltner and Jansen (2015) investigated the relationship between high body awareness (elite athletes and patients with anorexia nervosa) and mental rotation ability. Their results showed that both experimental groups exhibited better mental rotation performance than the control group. A recent study found that adolescent soccer players who had a 10-week specific soccer training with the nondominant leg showed a significantly larger increase in mental rotation ability than the control group who had trained with the nondominant foot (Pietsch \& Jansen, 2018). Moreover, Moreau (2012) conducted a study in which elite wrestlers and nonathletes completed mental rotation tasks with movement and image interference, and the results showed that the wrestlers' performance was impacted more than that of the nonathletes by movement interference, although both groups were affected by image interference. Thus, the results of these studies indicate that sports experts rely heavily on motor processes in mental rotation tasks. Additionally, the factor of physical movement was investigated to clarify how motor processes are involved in mental rotation. Moreau (2013) asked wrestlers and nonathletes to perform a mental rotation task with both hands constrained or unconstrained. The wrestlers exhibited higher performance than nonathletes in the unconstrained condition, but the advantage for wrestlers disappeared when their hands were constrained, implying that motor execution may affect the process of mental rotation.
However, in addition to the spatial factors (i.e., image interference of movements of figures or movement constraints) evaluated by previous studies, it is becoming increasingly difficult to ignore the time constraint in assessing mental rotation in athletes. As another performance factor, the time constraint has been found to have a critical effect on the motor processes of mental rotation (Goldstein, Haldane, \& Mtchell, 1990; Voyer, 1997). Embodied cognition has also emphasized the time constraint. In sports, which require the capacity to update strategies and rapidly change reactions, this kind of situational cognitive ability must deal with the constraints of "real time" or "runtime", and thus, cognition is under a time pressure (Wilson, 2002). A meta-analysis confirmed that the time constraint could influence the performance of mental rotation (Voyer, 2011). According to Heinen et al. (2012), adding time constraints would be helpful for observing the effect of sensory-motor experience on cognitive processing. Additionally, in the context of sports, the requirements of movement quality (direction, angle, speed, etc.) are characterized by the time constraint. For example, a mid-field player should pass the football before the opposing player arrives, and a diver must complete a series of movements before entering the water; in either case, if there is any delay, the time period for the successive movement will be reduced. Moreover, a previous study indicated that gymnasts were able to autonomously accelerate the imagery of the action during a short time period before the competition (Calmels \& Fournier, 2001). Therefore, athletes seem to adapt to the temporal context of the situation and try to maintain their level of mental rotation performance. Alternatively, the performance of nonathletes may be considerably more impeded by the time constraint.

Also important in the present study were the stages of the mental rotation process, perceptual stages (perceptual processing, stimuli identification and discrimination, and orientation identification), rotation stages (mental rotation and parity judgement), and decision stages (response selection and execution, Heil \& Rolke, 2002; Shepard \& Cooper, 1986). According to Wright, Thompson, Ganis, Newcombe, and Kosslyn (2008), the individual contributions of particular stages cannot be specified by overall performance. Thus, RTs are decomposed to reflect two components: the slope and the intercept of the RT's function at every angular disparity. The slope represents the process of the rotation stages and the intercept represents the processes of perceptual and decision stages (Jansen, Lehmann, \& Van Doren, 2012; Just \& Carpenter, 1985). Previous studies with object-based transformations have shown that even though athletes showed expertise in perceptual and decision stages, they failed to outperform nonathletes in the speed of mental rotation with body materials (Jansen et al., 2012). Alternatively, Ozel, Larue, and Molinaro (2002) reported better performance for sports experts in the rotation stages of mental rotation. Thus, the performance of individuals in different stages of egocentric mental rotation and whether their performance will change under a time constraint remains unclear. Further, it is unknown if athletes are able to outperform nonathletes when confronting a time constraint and what stage(s) would potentially contribute to this effect. Studies bearing the viewpoint of embodied cognition have demonstrated that physical movement and motor imagery share a common process and 
that accelerating the speed of motor rotation would correspondingly speed up the mental rotation process (Wexler, Kosslyn, \& Berthoz, 1998; Wohlschläger \& Wohlschläger, 1998). Diving is artistic jumping from a platform (i.e., platform diving or springboard diving) that includes abundant rotation skills (i.e., twist, somersault) and employs different body axes (head-feet, front-back, and left-right). To the best of our knowledge, the best divers can accelerate their rotation when the jumping is delayed or the diver fails to obtain an adequate height. Therefore, divers may accelerate mental rotation speed better than nonathletes in the egocentric tasks with time constraints.

In addition, in studies concerning mental rotation, far too little attention has been paid to adolescent athletes. A recent meta-analysis found that participants in all the studies examined were older than 17 (Voyer \& Jansen, 2017), which may be because sport expertise was developed over at least ten years of practice or with deliberate practice that begins in childhood (Ericsson, Krampe, \& Tesch-Römer, 1993). In fact, some studies have demonstrated better mental rotation ability for children who regularly participate in sports training than those who do not. Jansen, Lange, and Heil (2011) assessed the mental rotation ability of two groups of girls aged 9-14 years and indicated that the experimental group, who participated in juggling training for 3 months, performed significantly better than the controls, who did light strength training. Moreover, additional studies have found a positive relationship between motor ability and the accuracy of mental rotation tasks among primary school-aged and younger children (Jansen \& Heil, 2010; Jansen \& Kellner, 2015).

The present study aimed to link the time constraint in sports to a mental body rotation task in order to provide evidence of time processing of spatial transformation in light of embodied cognition. In particular, we illustrated the mental rotation (including the stages) performance under a time constraint and conducted three experiments. In Experiment 1, divers and nonathletes participated in an untimed MBRT and we hypothesized that the divers would outperform the nonathletes (Hypothesis 1). Because few studies have manipulated RTs of each trial in a mental rotation task, a response deadline, proposed by Benson Iii and Beach (1996), was utilized to manage the time constraint in Experiments 2 and 3. Accordingly, Hypothesis 2 asserted that the time constraint would impede the divers less than the nonathletes, and Hypothesis 3-that the divers will keep the advantage under a time constraint by accelerating not only the speed of the perceptual and decision stages but also the speed of rotation stages.

\section{EXPERIMENT 1: \\ MENTAL ROTATION TASK WITHOUT TIME CONSTRAINTS}

\section{Materials and Methods}

\section{PARTICIPANTS}

Forty-seven adolescent participants, including 24 elite diving athletes ( 11 males), aged 12 to 16 years $(M=14.41$ years; $S D=2.13)$, and 23 nonathletes (11 males), aged 13 to 15 years $(M=13.91$ years; $S D=0.53)$, participated in the experiment. The group of athletes consisted of divers from the Shanghai diving team; the training age was between 8 and 13 years, and they had approximately 30 hours of diving practice per week. The group of nonathletes consisted of middle school students who had never participated in professional sports training. The two groups did not vary in terms of their ages, $t(42)=1.07$, $p=.30, d=.32$. This study was approved by the Ethics Committee of the Shanghai University of Sport (2017036), and informed consent was obtained from the participants and their parents prior to participation.

\section{APPARATUS AND STIMULI}

In the MBRT, the stimulus was the back of a female wearing a dark swimsuit with the elbow of one arm on the head and the other arm placed on the waist (see Figure 1). The stimuli were presented at a size of $4 \times 4 \mathrm{~cm}$ at six angles $\left(0^{\circ}, 30^{\circ}, 60^{\circ}, 90^{\circ}, 120^{\circ}, 150^{\circ}\right.$, and $\left.180^{\circ}\right)$ on a black tablet screen. The stimuli appeared in black and white; the luminosity of the dark grey (colour of the swimsuits) was $30 \mathrm{~cd}$ / $\mathrm{m} 2$, the luminosity of the light grey (colour of the arms and legs of the body) was $80 \mathrm{~cd} / \mathrm{m} 2$, and the luminosity of the white background was $100 \mathrm{~cd} / \mathrm{m} 2$. The task was designed and displayed with E-Prime 2.0 (Psychology Software Tools, Sharpsburg, Pennsylvania) on three ThinkPad laptops with 14 in. screens.

\section{PROCEDURE}

Experiment 1 was an untimed constraint (UTC) MBRT that served as a reference for the time constraint. Participants were tested individually in a quiet room at the Shanghai University of Sport. Participants completed a questionnaire with demographic information and were seated in front of a screen at a distance of $60 \mathrm{~cm}$. The experiment consisted of 2 (laterality) $\times 7$ (angle) $\times 10$ (repetition) trials for a total of

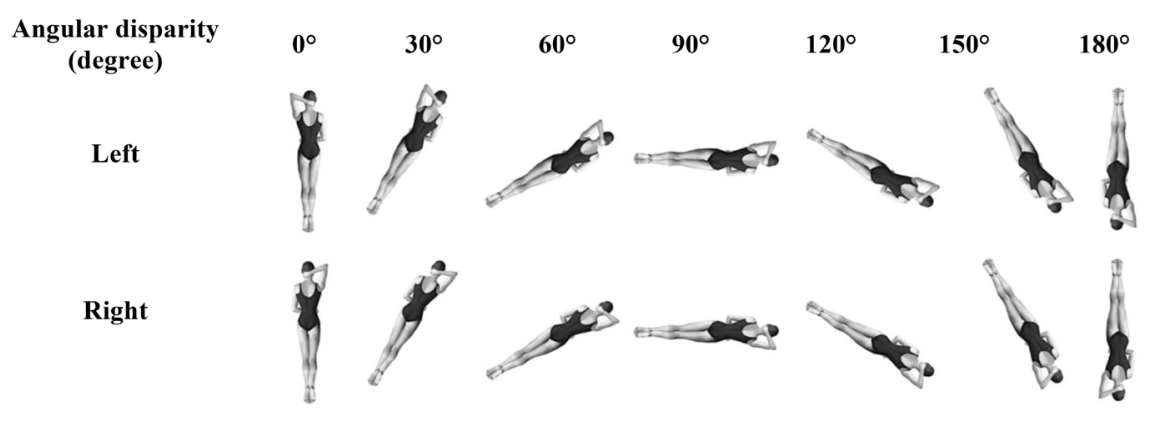

FIGURE 1.

Stimuli for the mental rotation task. Copyright by QA International, 2017. All rights reserevd. 
140 trials. After task instructions, the participants first conducted ten practice trials. The experimental trials began if their practice accuracy was above $75 \%$. Two subjects practised twice to reach the criterion. In each trial, the screen showed a fixation ( $1 \mathrm{~s}$ to $1.5 \mathrm{~s}$ ). Then, the stimulus was presented, and participants were asked to determine as accurately and rapidly as possible which arm the female had the elbow of placed over her head. The stimulus disappeared when either the $F$ (left) or $J$ (right) key was pressed or more than $3 \mathrm{~s}$ had elapsed. Subsequently, the screen went blank for $1 \mathrm{~s}$, and then the next trial began. The entire experiment took approximately $40 \mathrm{~min}$.

\section{STATISTICAL ANALYSES}

One athlete and one nonathlete were excluded due to having RTs that were more than three SDs above the mean or ERs above 25\% (the two subjects were excluded in Experiments 2 and 3), and RTs for incorrect trials $(2 \%)$ were excluded. The RTs were transformed into a logarithmic base (ln) to obtain a normal distribution $(z<1.10, p\rangle$ .18 , in all instances). Normal distributions were observed for the ERs ( $z<.76, p>.62$, in all instances). To test Hypothesis 1, two analyses of variance (ANOVA) were calculated for the dependent variables RT and $\mathrm{ER}$, with the between-subjects factor of group (divers, nonathletes) and the within-subject factor of angular disparity $\left(0^{\circ}, 30^{\circ}, 60^{\circ}, 90^{\circ}, 120^{\circ}\right.$, $150^{\circ}$, and $\left.180^{\circ}\right)$. Bonferroni post hoc tests were applied to identify the specific interactions. Moreover, the RT functions of angular disparity were presented for each combination of group. The slope of the linear component of the RT function represents the millisecond increment in RT associated with a $1^{\circ}$ increment in orientation. Thus, the inverse of the slope multiplied by 1000 shows the mental rotation speed, which is how many degrees could be rotated in one second. Moreover, the intercept represents the RT at the angular disparity of $0^{\circ}$, which is a good estimator of the components of task performance other than the rotation stages, including stimulus encoding and responding (Yu \& Zacks, 2015). To test the stages performance, two independent-samples t tests were conducted to compare the mental rotation speed and $\mathrm{RT}$ at $0^{\circ}$ of the two groups.

\section{Results}

\section{REACTION TIME}

The ANOVA for RTs showed main effects of group, $F(1,44)=4.85$, $p<.05, \eta_{\mathrm{p}}{ }^{2}=.10$, and angle, $F(6,264)=206.63, p<.001, \eta_{\mathrm{p}}{ }^{2}=.83$, but no interaction was found between these variables, $F(6,264)=.55$, $\left.\mathrm{p}=.65, \eta_{\mathrm{p}}{ }^{2}=.01\right]$. Specifically, the divers had a mean RT of $896 \mathrm{~ms}$ $(S D=221)$, and the nonathletes had a mean RT of $1062 \mathrm{~ms}(S D=614)$. proportion.

\section{ERROR RATE}

The ANOVA for ERs demonstrated a main effect of angle, $F(6,264)=13.02, p<.001, \eta_{\mathrm{p}}{ }^{2}=.24$, but the main effect for the factor of group, $F(1,44)=.03, p=.86, \eta_{\mathrm{p}}{ }^{2}=.001$, and the interaction between the two factors, $F(6,264)=.70, p=.55, \eta_{\mathrm{p}}{ }^{2}=.02$, were not significant (athletes: $M=.02, S D=.003$; nonathletes: $M=.02, S D=.005$ ).

\section{MENTAL ROTATION STAGES}

The independent-samples $\mathrm{t}$ tests indicated that the divers $(M=$ $631.31 \mathrm{~ms}, S D=109.15)$ exhibited faster perception and decisionmaking than nonathletes $(M=809.45 \mathrm{~ms}, S D=321.55)(t=3.21, p<$ $.001, d=.87)$. Moreover, the results of $\mathrm{t}$ tests revealed that the mental rotation speed was faster for divers $\left(M=119^{\circ} / \mathrm{s}, S D=30^{\circ} / \mathrm{s}\right)$ than for nonathletes $\left(98^{\circ} / \mathrm{s}, S D=27^{\circ} / \mathrm{s}, t=2.824, p<.01\right)$.

\section{DISCUSSION}

Experiment 1 demonstrated that divers outperformed nonathletes independent of the angular disparity in the MBRT. Regarding the previous result, the stimulus of posture in sport rather than a more general one could account for this effect. Therefore, the divers' kinaesthetic experience facilitated the process of mental rotation due to the conformity of sports movements and the characteristics of the tasks (Feng, Zhang, Ji, Jia, \& Li, 2017; Jola \& Mast, 2005). Additionally, the RT results in this experiment served as a reference for the time constraint in Experiments 2 and 3.

\section{EXPERIMENT 2:}

\section{MENTAL ROTATION TASK WITH} A RELATIVE TIME CONSTRAINT

\section{Materials and Methods}

\section{PARTICIPANTS}

The participants were the same as in Experiment 1.

\section{APPARATUS AND STIMULI}

The apparatus and stimuli were the same as in Experiment 1.

\section{PROCEDURE}

Experiment 2 was a MBRT with a relative time constraint (TC). Regarding the setting of the time constraint, Benson Iii and Beach (1996) obtained the $M$ of all the subjects subtracted from its $S D$ to obtain the TC. However, their RT and SD values are $191 \mathrm{~s}$ and $67 \mathrm{~s}$, respectively, which are much longer than those in our experiment. Therefore, in Experiment 2, we calculated the TC by subtracting $1 / 2$ of the $S D$ of all the subjects' RT from the $M$ of each group's RT. Additionally, Experiment 1 shows that there is a group difference in RT, which is that the divers respond faster. Based on this, we intended to select two different TCs for the two groups (see Table 1).

Experiment 2 was conducted two weeks after Experiment 1. In Experiment 2, participants were tested individually in a quiet room. The experiment consisted of 2 (laterality) $\times 7$ (angle) $\times 10$ (repetition) trials for a total of 140 trials. In each trial, the screen showed a fixation ( $1 \mathrm{~s}$ to $1.5 \mathrm{~s}$ ). Then, the stimulus was presented, and participants were asked to determine as accurately and rapidly as possible which arm the female had the elbow of placed over her head. Each judgement had a time pressure, and if subjects did not press the $F$ (left) or $J$ (right) key 


\begin{tabular}{lcc}
\hline \multicolumn{3}{l}{ TABLE 1. } \\
The Relative Time Constraint (TC) in Experiment 2 \\
\hline Group & $\mathbf{R T}_{\text {UTC }}(\mathbf{m s})$ & TC $=\boldsymbol{M}_{\text {group }}-\mathbf{1} / \mathbf{2} \mathbf{S D}_{\text {all }}(\mathbf{m s})$ \\
\hline Divers & $827 \pm 175$ & 591 \\
Non-athletes & $1136 \pm 614$ & 900 \\
All & $982 \pm 472$ & \\
\hline
\end{tabular}

Note. UTC $=$ untimed constraint.

within the specified time, it was considered an error. Subsequently, the screen went blank for $1 \mathrm{~s}$ and then the next trial began. After reading the task instructions, participants conducted ten practice trials. All subjects practised once to reach the criterion. The entire experiment took approximately $35 \mathrm{~min}$.

\section{STATISTICAL ANALYSES}

The RTs were transformed into a logarithmic base (ln) to obtain a normal distribution $(z<.73, p>.66$, in all instances), and normal distributions were observed for the RTs in TC condition and the ERs $(z<1.32, p>.06$, in all instances). Because the ERs at large angles were very low, RTs for incorrect trials were included to examine the effect of time on RTs. In addition, the function between RT and angular disparity was calculated for each combination of conditions and groups. To test Hypothesis 2, two ANOVAs were performed for the dependent variables RT and ER, with the between-subjects factor of group (divers, nonathletes) and the within-subject factor of the angular disparity $\left(0^{\circ}\right.$, $30^{\circ}, 60^{\circ}, 90^{\circ}, 120^{\circ}, 150^{\circ}$, and $180^{\circ}$ ) and condition (UTC, TC, where the UTC data are from Experiment 1). Concerning Hypothesis 3, two ANOVAs were performed for the dependent variables of mental rotation speed and RT at $0^{\circ}$, with the between-subjects factor of group (divers, nonathletes) and the within-subject factor of condition (UTC, TC). Bonferroni post hoc tests were applied to identify the specific interactions. Moreover, in case of different speed-accuracy trade-offs for two groups, we used inverse efficiency scores (IE) to measure them (Steggemann et al., 2011). The IE is the M of RT divided by the accuracy, and a t test was conducted with the dependent variable of IE and the between-subjects factor of the group.

\section{Results}

\section{REACTION TIME}

The ANOVA results demonstrated the main effects of group, $F(1,44)=15.58, p<.001, \eta_{\mathrm{p}}^{2}=.29$ ], with the divers presenting faster RTs $(M=701 \mathrm{~ms}, S D=29)$ than the nonathletes $(M=833 \mathrm{~ms}$, $S D=323$, see Figure 2). Main effects of angle, $F(6,264)=331.89, p<$ $.001, \eta_{\mathrm{p}}^{2}=.90$, condition, $F(1,44)=137.51, p<.001, \eta_{\mathrm{p}}{ }^{2}=.78$, and their interaction, $F(6,264)=53.65, p<.001, \eta_{\mathrm{p}}^{2}=.58$, were found.

\section{ERROR RATE}

The ANOVA results revealed the main effects of group, $F(1,44)$ $=15.31, p<.001, \eta_{\mathrm{p}}{ }^{2}=.27$, angle, $F(6,264)=154.42, p<.001, \eta_{\mathrm{p}}{ }^{2}=$ .79 , and condition, $F(1,44)=317.24, p<.001, \eta_{p}{ }^{2}=.88$. Additionally, there was a significant interaction between group and angle, $F(6,264)$ $=4.21, p<.01, \eta_{\mathrm{p}}{ }^{2}=.09$, group and condition, $F(1,44)=15.42, p<$ $.001, \eta_{\mathrm{p}}{ }^{2}=.27$, angle and condition, $F(6,264)=116.48, p<.01, \eta_{\mathrm{p}}{ }^{2}=$
.74 , and among group, angle, and condition, $F(6,264)=4.19, p<.01$, $\eta_{\mathrm{p}}{ }^{2}=.09$, see Figure 3). Post hoc tests revealed that in the TC condition, nonathletes $\left(120^{\circ}: M=.18, S D=.11,150^{\circ}: M=.34, S D=.16\right)$ were more accurate than divers $\left(120^{\circ}: M=.33, S D=.26,150^{\circ}: M=.59\right.$, $S D=.21)$ at the angles of $120^{\circ}(t=2.69, p<.05)$ and $150^{\circ}(t=2.76, p$ $<.01$, see Figure 3).

\section{SPEED-ACCURACY TRADE-OFF}

The $t$ test results revealed significant group differences $(t=-2.04$, $p<.05)$, indicating that the speed-accuracy trade-offs of divers (685 \pm $87)$ and non-athletes $(728 \pm 44)$ are different in this experiment.

\section{MENTAL ROTATION STAGES}

The results of mental rotation stages are not shown because Hypothesis 2 has not been confirmed.

\section{DISCUSSION}

Previous research on time constraints in mental rotation was based on the results of a paper-and-pencil test (Voyer, 2011). In Experiment 2 , as an attempt, the TC was $900 \mathrm{~ms}$ for the nonathletes and $591 \mathrm{~ms}$ for the divers, based on the performance of the UTC MBRT. The divers' response under the TC condition was found to be significantly faster than that of nonathletes, indicating that divers can better adapt to the TC situation. However, concerning the ER, we found that the ER of $120^{\circ}$ and $150^{\circ}$ for divers under the TC condition was significantly lower than that of nonathletes, which is inconsistent with our experimental assumptions. The literature suggests that the reaction deadline (RD) is an experimental paradigm that can significantly induce speedaccuracy trade-offs (Seya \& Mori, 2015). The results showed that the inconsistency between the results and our hypotheses may be due to a speed-accuracy trade-off of divers and nonathletes under the TC condition. Specifically, the athletes had to make more mistakes in order to meet time requirements.

The results may be explained by different time constraint settings. Divers may feel much greater pressure than nonathletes (because their time pressure is nearly $300 \mathrm{~ms}$ shorter than that of nonathletes). Therefore, there is reason to believe that the divers had to improve performance even when their RTs were very short. Nonetheless, the

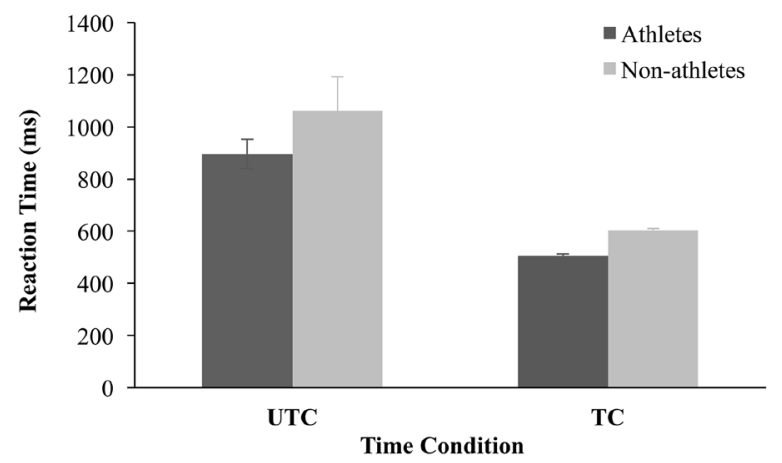

\section{FIGURE 2.}

Reaction times (Mean and SE) for each group and each condition in Experiment 2. 
divers' ER at $180^{\circ}$ was not significantly different from that of nonathletes, which indicates that the sports experience compensates the declines in performance for the divers under high time pressure. Though Experiment 2 failed to find the RT advantage of the divers under TC, both the divers and the nonathletes responded faster than the TC standard (athletes and nonathletes were $85 \mathrm{~ms}$ and $296 \mathrm{~ms}$ faster, respectively). Bronner (1972) suggests that time pressure is generated when the perceived time is insufficient; thus, the most important thing for subjects is to think that time is limited (Dan \& Dan, 2001). Moreover, the unified (absolute) RD is also a common method for investigating time constraints (Benikos, Johnstone, \& Roodenrys, 2013; Seya \& Mori, 2015). Therefore, an absolute TC was utilized in Experiment 3 to test the role of TC in the divers' and nonathletes' performance of mental rotation.

\section{EXPERIMENT 3:}

\section{MENTAL ROTATION TASK WITH AN ABSOLUTE TIME}

\section{Materials and Methods}

\section{PARTICIPANTS}

The participants were the same as in Experiment 1.

\section{APPARATUS AND STIMULI}

The apparatus and stimuli were the same as in Experiment 1.

\section{PROCEDURE}

The procedure was the same as in Experiment 2. Experiment 3 used an MBRT with an absolute time constraint (TC). However, unlike Experiment 2, the mean of RT in all participants was subtracted from the value of $1 / 2$ a $S D$. The absolute TC standard is shown in Table 2. Experiment 3 was conducted the day after Experiment 2. In Experiment 3, absolute time constraints were added to the task, and all other procedures remained the same as that of Experiment 2.

\section{STATISTICAL ANALYSES}

The RTs were transformed into a logarithmic base (ln) to obtain a normal distribution ( $z<.76, p>.62$, in all instances), and normal distributions were observed for the RTs in the TC condition and the ERs $(z<1.91, p>.18$, in all instances). RTs for incorrect trials were included to examine the effect of time on RTs. In addition, the function between RT and angular disparity was calculated for each combination of conditions and participants. The ANOVAs were performed as in Experiment 2.

\section{Results}

\section{REACTION TIME}

The ANOVA demonstrated main effects of group, $F(1,42)=7.28$, $p<.01, \eta_{\mathrm{p}}^{2}=.15$, with divers presenting faster RTs $(M=725 \mathrm{~ms}$, $S D=128)$ than nonathletes $(M=830 \mathrm{~ms}, S D=325)$. The main effects of angle, $F(6,252)=349.35, p<.001, \eta_{\mathrm{p}}{ }^{2}=.90$, and condition, $F(1,42)$ $=134.23, p<.001, \eta_{\mathrm{p}}{ }^{2}=.77$, and their interaction, $F(6,252)=50.92$, $p<.001, \eta_{\mathrm{p}}^{2}=.56$, were found.

\section{ERROR RATE}

The ANOVA results revealed main effects of group, $F(1,42)=4.37$, $p<.05, \eta_{\mathrm{p}}{ }^{2}=.09$, angle, $F(6,252)=5.73, p<.001, \eta_{\mathrm{p}}{ }^{2}=.71$, and condition, $F(1,42)=214.23, p<.001, \eta_{\mathrm{p}}{ }^{2}=.84$. Additionally, there was a significant interaction between group and angle, $F(6,252)=3.94$, $p<.05, \eta_{\mathrm{p}}{ }^{2}=.09$, group and condition, $F(1,42)=4.50, p<.05, \eta_{\mathrm{p}}{ }^{2}=$ .10 , angle and condition, $F(6,252)=3.94, p<.05, \eta_{\mathrm{p}}{ }^{2}=.09$, and among group, angle, and condition, $F(6,252)=3.30, p<.05, \eta_{\mathrm{p}}{ }^{2}=.03$ (see Figure 5). Post hoc tests revealed that in TC conditions, divers $\left(150^{\circ}: M\right.$ $\left.=.25, S D=.21,180^{\circ}: M=.40, S D=.23\right)$ were more accurate than nonathletes $\left(150^{\circ}: M=.34, S D=.16,180^{\circ}: M=.59, S D=.22\right)$ at angles of $150^{\circ}(t=1.20, p=.10)$ and $180^{\circ}(t=2.82, p<.01)$. In addition, in the TC condition, the ER of the two groups changed with the adjacent angle differently. The nonathletes had a significant increase in ER between each adjacent angle from $90^{\circ}$ to $180^{\circ}\left(90^{\circ}: .04 \pm .07,120^{\circ}\right.$ : .18..11, $150^{\circ}$ : $.34 \pm .16,180^{\circ}: .59 \pm .22$, all $\left.p<.01\right)$, but the divers showed ER differences only between $90^{\circ}(.05 \pm .08)$ and $120^{\circ}(.20 \pm .18, p<.01)$.

\section{MENTAL ROTATION STAGES}

The ANOVA results for perceptual and decision stages showed significant main effects of the factors for group, $F(1,42)=11.16, p$ $<.01, \eta_{\mathrm{p}}{ }^{2}=.21$, and condition, $F(1,42)=37.04, p<.001, \eta_{\mathrm{p}}{ }^{2}=.47$, but the interaction between these variables was not significant, $F(1,42)=2.44, p=.13, \eta_{\mathrm{p}}{ }^{2}=.06$. This finding indicates that the divers (UTC: $M=631 \mathrm{~ms}, S D=109$; TC: $M=457 \mathrm{~ms}, S D=45$ ) exhibited faster cognition and decision-making than nonathletes (UTC: $M=809$ $\mathrm{ms}, S D=322$; TC: $M=515 \mathrm{~ms}, S D=54$ ) regardless of the time condition (see Figure 6). The main effects of condition showed that the RT at $0^{\circ}$ of the two groups in the TC condition ( $\left.M=486 \mathrm{~ms}, S D=57\right)$ was faster than that in the UTC condition ( $M=720 \mathrm{~ms}, S D=254)$.

The ANOVA results for the rotation stages indicated significant main effects of the factors for group, $F(1,42)=12.19, p<.01, \eta_{p}^{2}$ $=.23$, and condition, $F(1,42)=216.43, p<.001, \eta_{\mathrm{p}}{ }^{2}=.84$. Figure 7 presents the results of the post hoc tests, showing that the divers

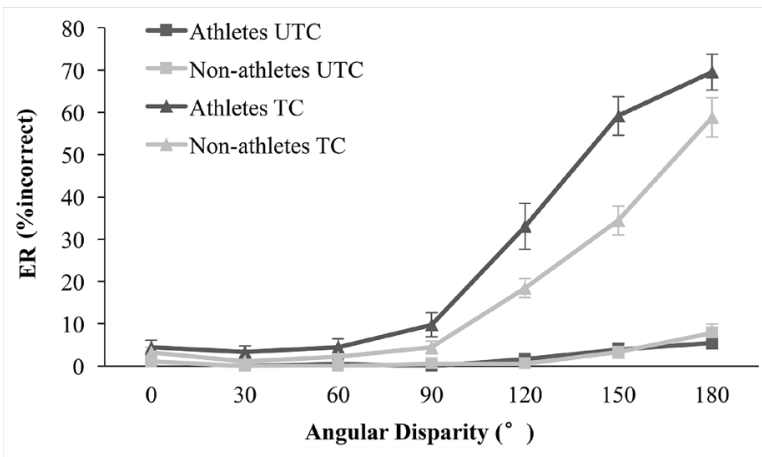

FIGURE 3.

Error rate (mean and SE) for each group and condition at each angle disparity in Experiment 2. 
TABLE 2

The Absolute Time Constraint (TC) in Experiment 3

\begin{tabular}{ccc}
\hline Group & RT $_{\text {UTC }}(\mathbf{m s})$ & $\mathbf{T C}=\boldsymbol{M}_{\text {group }}-1 / 2 \mathbf{S D}_{\text {all }}(\mathbf{m s})$ \\
\hline Divers & $827 \pm 175$ & 746 \\
Non-athletes & $1136 \pm 614$ & 746 \\
All & $982 \pm 472$ & \\
\hline
\end{tabular}

Note.UTC $=$ untimed constraint.

(UTC: $M=119 \%$ s, $S D=30 \%$; TC: $M=176 \%$, $S D=11 \%$ ) were faster than the nonathletes (UTC: $98^{\circ} / \mathrm{s}, S D=27 \%$; TC: $M=163^{\circ} / \mathrm{s}$, $S D=7 \%$ s) in both conditions, and the mental rotation speed of both groups in the TC condition $\left(M=169^{\circ} / \mathrm{s}, S D=11^{\circ} / \mathrm{s}\right)$ was significantly faster than that in the UTC condition $\left(M=108^{\circ} / \mathrm{s}, S D=30^{\circ} / \mathrm{s}\right)$. However, a significant interaction between group and condition was not found, $F(1,42)=0.71, p=.41, \eta_{\mathrm{p}}^{2}=.02$.

\section{DISCUSSION}

Experiment 3 employed an absolute TC to investigate the influence of time on divers' and nonathletes' mental rotation ability. The results demonstrated that in the TC condition, the divers' ER was significantly lower than that of the nonathletes, and their advantage of RT still existed. Thus, the results showed that the divers were better able to deal with the situation of time pressure, verifying Hypothesis 2 . The rationale for an absolute TC may be explained as follows: (a) Similar to Experiment 2, all subjects significantly accelerated their RT and increased their ER, which was consistent with our study purpose and was supported by the results of previous studies (Liesefeld, Fu, \& Zimmler, 2015). (b) The divers demonstrated shorter RTs and lower ERs in the TC condition, which showed there was no speed-accuracy trade-offs.

The RT at $0^{\circ}$ (performance of perceptual and decision stages) and the mental rotation speed (performance of rotation stages) of the athletes and nonathletes were compared in both UTC and TC conditions. The results revealed that in the TC condition, the RT at $0^{\circ}$ of the divers and the nonathletes became significantly shorter, and the mental rotation speed improved significantly. In addition, the significant main effects of group supported Hypothesis 3. As mentioned above, the theory of embodied cognition presents that various axes of the body can be drawn onto the embodied body (i.e., using a body to imitate an object, Decety, 2002; Vereza, 1999). Thus, we believe that the divers' advan-

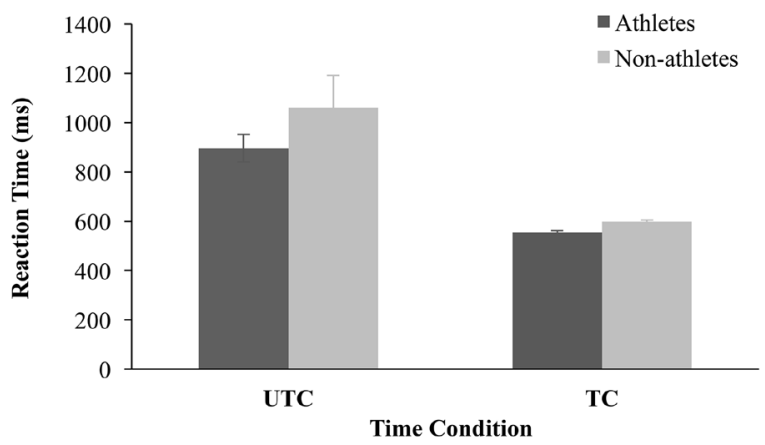

FIGURE 4.

Reaction time (mean and SE) for each group and each condition in Experiment 3. tage in perceptual and decision stages is due to spatial embodiment, which contributes to the recognition of the body pose and orientation (Amorim, Isableu, \& Jarraya, 2006). In addition, motoric embodiment contributes to the maintenance of the spatial configuration throughout the mental rotation process (Amorim et al., 2006) and thus improves the rotation speed.

\section{GENERAL DISCUSSION}

In light of the embodied cognition viewpoint, the present study is the first to examine the effect of time constraints on egocentric mental rotation in individuals with different levels of sports expertise. Additionally, the present study aimed to clarify the stages of mental rotation under conditions with and without a TC. The performance of rotational sports experts (elite divers) was compared to that of nonathletes in an MBRT with sportspecific body figures.

The divers exhibited faster RTs than the nonathletes in the UTC condition, supporting Hypothesis 1 . However, the divers did not present a significantly lower ER than the nonathletes, which is in line with the findings of studies by Jola and Mast (2005) and Steggemann et al. (2011). Notably, these findings concerned adolescent elite divers who had excellent performance (sixteen of twenty-four divers were in the top eight at national or international junior championships) and had practised diving for approximately ten years. Thus, the present study fills the gap of scarce data reported for adolescent participants, as mentioned by Voyer and Jansen (2017). The stage results in UTC showed that the divers exhibited faster perception, decision-making, and mental rotation speed, which is consistent with the results of our other study (Feng et al., 2017). Though a few studies have argued that motor experience may not benefit the rotation stages in mental rotation (Heppe, Kohler, Fleddermann, \& Zentgraf, 2016; Jansen et al., 2012), possible explanations were provided in the previous study (Feng et al., 2017).

According to embodied cognition, cognitive ability is closely related to the time factor in the situation. For Hypothesis 2, which was that TC would impede the divers less than the nonathletes, the performances of the divers and nonathletes were analysed in the UTC and TC conditions. When the absolute TC was set as $M-1 / 2 S D$ of all subjects in Experiment 3, the results showed that divers adapted to the pressure situation and thus performed with a significantly lower ER than nonathletes in the absolute TC condition. Additionally, the advantage of RTs for the divers was also confirmed in the absolute TC condition. This finding corroborates the conclusions of Goldstein et al. (1990) and Voyer (1997), who showed that the TC could influence the performance of participants. Further, in line with the viewpoint of embodied cognition (Wilson, 2002), this result provides experimental evidence for the relationship between mental rotation ability and the factor of time in a sports context. Additional explanations could be provided to explain the characteristics of the different stages in mental rotation.

Previous studies have shown that RT increased gradually as a function of angular disparity (Jola \& Mast, 2005; Shepard \& Metzler, 1971; Voyer \& Bryden, 1990), supporting the idea that the perception of humans is functionally equivalent to the physical phenomena surrounding the humans 


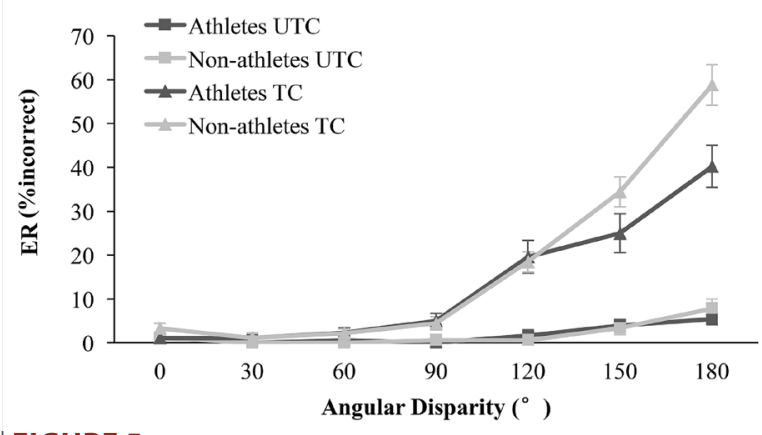

FIGURE 5.

Error rate (mean and SE) for each group and condition at each angle disparity in Experiment 3.

(Jolicoeur \& Kosslyn, 1985). In line with this finding, in the present study, the divers performed better in terms of ER than nonathletes at the $150^{\circ}$ and $180^{\circ}$ angles in the absolute TC condition, indicating that although the head-down posture is relatively rare, it was more familiar to the divers. Similarly, Steggemann et al. (2011) and Kaltner and Jansen (2015) demonstrated that motor experts benefited from having the human figure in unfamiliar orientations in an MBRT, which is explained by the process of motoric embodiment. As a type of embodied spatial transformation, motoric embodiment refers to the process of observing, imagining, or executing actions with the same motor representations (Decety, 2002; Vereza, 1999), which could be facilitated and primed when the divers mentally rotate the anatomically possible postures (Amorim et al., 2006).

In addition, in the absolute TC condition, the ER function of the angle showed that the two groups' performance at adjacent angles was different. The nonathletes displayed a significant increase in ER between each adjacent angle from $90^{\circ}$ to $180^{\circ}$, but the divers showed an ER difference only between $90^{\circ}$ and $120^{\circ}$. The results implied that the divers would be able to perform better for inverted figures. First, according to the embodied cognition, an individual's perception of the environment could affect his or her cognitive ability (Wilson, 2002). In the present study, the divers could adopt more body-related experience learned from the first-person perspective to accelerate the judgements of postures. Additionally, the difference in ER and angular relationship may indicate that the divers use different strategies than nonathletes. Previous research has revealed that the flipping strategy was shorter than that of the spinning strategy. Amorim et al. (2006) demonstrated that if mental rotation is performed piecemeal, then spurious mismatches in identical trials will produce a degradation of response accuracy with an angular difference. Accordingly, in previous studies, holistic strategies were generally considered to be associated with better mental rotation task (MRT) performance, and vice versa (Steggemann et al., 2011; Zhao \& Sala, 2018). In accordance with the time perception model, time pressure affects the processing of decision-making, which may lead to simple, nonlinear decision strategies (Dan \& Dan, 2001). This result is similar to that reported in the study by Moreau, Clerc, Mansy-Dannay, and Guerrien (2011), who found that athletes were more comprehensive and flexible in an MRT, while nonathletes preferred more singular strategies. Additionally, the superior performance of the athletes may be relevant to the flipping strategy but not the spinning strategy (Kanamori \& Yagi, 2002).
To test Hypothesis 3, the stages of performance of divers and nonathletes were evaluated. Consistent with our hypothesis, the results revealed that in the absolute TC condition, the advantage of the divers existed in perceptual stages, decision stages, and rotation stages (Amorim et al., 2006). Spatial embodiment has been proposed as another embodied spatial transformation (Amorim et al., 2006), in which the body axes can be mapped onto the embodied object (Decety, 2002; Vereza, 1999). In alignment with this, the mapping of the body's cognition (head-feet, left-right, and front-behind axes) for the divers was facilitated in the absolute TC condition, which then aided the shape-matching process. Kail, Carter, and Pellegrino (1979) proposed that differences in mental rotation speed may reflect differences in mental rotation strategies. Thus, a main effect for the group in terms of rotation stages is likely explained by different strategies between the divers and the nonathletes.

Interestingly, when changing from the UTC to the absolute TC condition, the athletes' speed for the rotation stages changed from $119 \%$ s to $176 \%$, but that of the nonathletes changed from $98 \%$ s to $163 \%$ s. Similarly, the RT of the divers varied from $631 \mathrm{~ms}$ to $457 \mathrm{~ms}$, while that of the nonathletes varied from $809 \mathrm{~ms}$ to $515 \mathrm{~ms}$, revealing that the performance of the nonathletes improved more than that of the divers. Although the interaction is not significant, we try to explain this result. In terms of the perception and decision, the MRBT we use is relatively easy. Exercise effects may appear after several repetitions. Studies have found that after practice, the subjects can directly trace from memory when performing the MRT (Provost, Johnson, Karayanidis, Brown, \& Heathcote, 2013); thus, the RTs at $0^{\circ}$ were improved. Additionally, while the rotation strategies seemed to be relatively settled, they could have been easily learned through practice. Moreover, the practice effects of participants during conducting three same experiment was tested. According to Provost et al. (2013), extensive practice with a small set of stimuli (10 stimulus pairs, similar to 7 pairs in present study) allowed participants to direct the retrieval from memory of the correct response associated with each stimulus. This strategy of practice effects would lead to shorter perceptual time of the subjects. However, RTs at $0^{\circ}$ of nonathletes decreased more may reflected that the divers' advantage was not due to their practice effects.

There are two limitations in the present study that need to be acknowledged. First, only one rotation axis, the front-back axis, was considered in our study, even though the divers often use more than one axis in practice. Moreover, based on the significant difference in RT between the groups in the UTC condition, setting the same TC condition for the two differ-

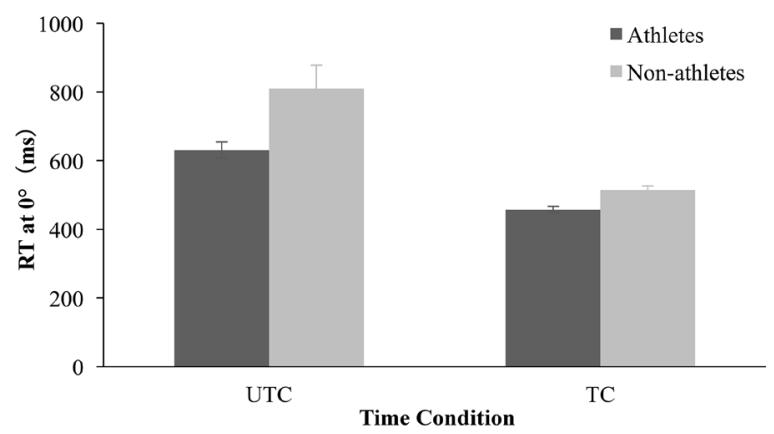

FIGURE 6.

Reaction times at $0^{\circ}$ (mean and $S E$ ) for each group in each time condition 


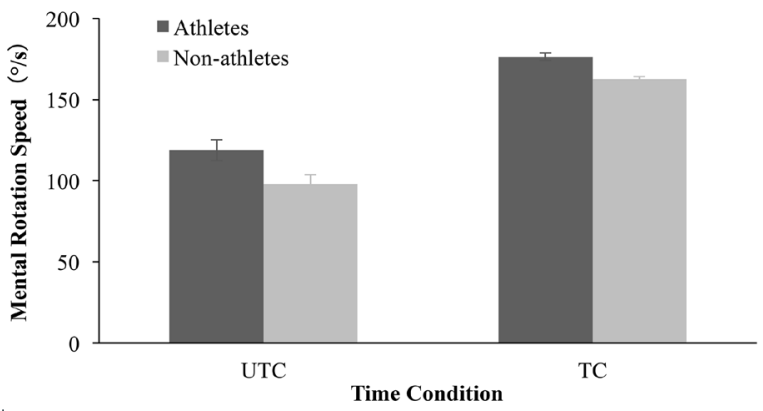

FIGURE 7.

Mental rotation speed (mean and $S E$ ) for each group in each time condition

ent groups seemed to create more pressure for the nonathletes, so their performance in the absolute TC condition declined more substantially than that of the divers. However, if a similar RT percentage was set for each group (i.e., $80 \%$ for each group), then the same time pressure would not have been created; it is harder for the divers because they have already performed a rather fast RT. Moreover, given that the RTs of the divers and the nonathletes in the absolute TC condition ( $457 \mathrm{~ms}$ and $515 \mathrm{~ms}$ ) were far below the time constraint $(800 \mathrm{~ms})$, we have reason to believe that the exact number of the time constraint is not vital.

\section{CONCLUSIONS}

The present study utilized a spatial factor (sport-specific stimuli) to assess the mental rotation ability of adolescent athletes and nonathletes and has, for the first time, confirmed the role of time in the relationship between sports expertise and mental rotation in light of the viewpoint of embodied cognition. The results showed that in the UTC condition, the divers exhibited faster RTs and better performance in both stages than the non-athletes. When the TC condition was administered, superior RTs and lower ER at large angles were confirmed for the divers. More precisely, the advantage of the divers in the TC condition was due to both faster perception and decision-making and faster mental rotation speed. These results could be extended to professions that require mental rotation ability under time pressure, such as pilots, surgeons, or security screeners (Hegarty \& Waller, 2005; Krüger \& Suchan, 2016).

\section{ACKNOWLEDGEMENTS}

The authors would like to thank the coaches of the diving team of Shanghai, Huiguo Shi and Xiaoling Yu, as well as the students' teacher, Chao Li, for their assistance with the experiment.

\section{REFERENCES}

Amorim, M.-A., Isableu, B., \& Jarraya, M. (2006). Embodied spatial transformations: "Body analogy" for the mental rotation of objects. Journal of Experimental Psychology. General, 135, 327-347. doi: 10.1037/0096-3445.135.3.327 السلس الس

Benikos, N., Johnstone, S. J., \& Roodenrys, S. J. (2013). Varying task difficulty in the Go/Nogo task: The effects of inhibitory control, arousal, and perceived effort on ERP components.
International Journal of Psychophysiology, 87, 262-272. doi: 10.1016/j.ijpsycho.2012.08.005 السلسلس

Benson lii, L., \& Beach, L. R. (1996). The effects of time constraints on the prechoice screening of decision options. Organizational Behavior and Human Decision Processes, 67, 222-228. doi: https://doi.org/10.1006/obhd.1996.0075 السلسلس

Bronner, R. (1972). Decision making under time pressure. Lexington MA: Lexington Books.

Calmels, C., \& Fournier, J. F. (2001). Duration of physical and mental execution of gymnastic routines. Sport Psychologist, 15,

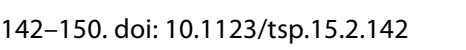

Dan, A., \& Dan, Z. (2001). A timely account of the role of duration in decision making. Acta Psychologica, 108, 187-207. doi:

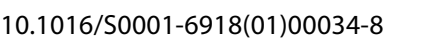

Decety, J. (2002). Is there such a thing as functional equivalence between imagined, observed and executed action? In A. N. Meltzoff \& W. Prinz (Eds.), The imitative mind: Development, evolution, and brain bases (pp. 291-310). Cambridge, MA: Cambridge University Press.

Ericsson, K. A., Krampe, R. T., \& Tesch-Römer, C. (1993). The role of deliberate practice in the acquisition of expert performance. Psychological Review, 100, 363-406. doi: 10.1037//0033295X.100.3.363 س山س

Feng, T., Zhang, Z., Ji, Z., Jia, B., \& Li, Y. (2017). Selective effects of sport expertise on the stages of mental rotation tasks with object-based and egocentric transformations. Advances in Cognitive Psychology, 13, 248-256. doi: 10.5709/acp-0225-x المالسلكالس in Goldstein, D., Haldane, D., \& Mtchell, C. (1990). Sex differences in visual-spatial ability: The role of performance factors. Memory \& Cognition, 18, 546-550. doi: 10.3758/BF03198487 |سلس

Habacha, H., Molinaro, C., Tabben, M., \& Lejeune-Poutrain, L. (2014). Implementation of specific motor expertise during a mental rotation task of hands. Experimental Brain Research, 232, 3465-3473. doi: 10.1007/s00221-014-4029-3 سلس

Hegarty, M., \& Waller, D. (2005). Individual differences in spatial abilities. In P. Shah \& A. Miyake (Eds.), The Cambridge handbook of visuospatial thinking (pp. 121-169). Cambridge, MA: Cambridge University Press.

Heil, M., \& Rolke, B. (2002). Toward a chronopsychophysiology of mental rotation. Psychophysiology, 39, 414-422. doi: 10.1017.

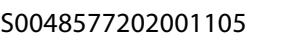

Heinen, T., Jeraj, D., Vinken, P. M., \& Velentzas, K. (2012). Rotational preference in gymnastics. Journal of Human Kinetics, 33, 33-43. doi: 10.2478/v10078-012-0042-4 |لمالس

Heppe, H., Kohler, A., Fleddermann, M.-T., \& Zentgraf, K. (2016). The relationship between expertise in sports, visuospatial, and basic cognitive skills. Frontiers in Psychology, 7, 1-14. doi: 10.3389/fpsyg.2016.00904 سلس الس

Hoyek, N., Champely, S., Collet, C., Fargier, P., \& Guillot, A. (2014). Is mental rotation ability a predictor of success for motor performance? Journal of Cognition and Development, 15, 495-505. doi: 10.1080/15248372.2012.760158 السلس 
Ionta, S., \& Blanke, O. (2009). Differential influence of hands posture on mental rotation of hands and feet in left and right handers. Experimental Brain Research, 195, 207-217. doi: 10.1007/s00221-009-1770-0 كالس

Jansen, P., \& Heil, M. (2010). The relation between motor development and mental rotation ability in 5- to 6-tear-old children. European Journal of Developmental Science, 4, 66-74. doi:

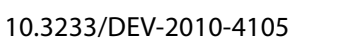

Jansen, P., \& Kellner, J. (2015). The role of rotational hand movements and general motor ability in children's mental rotation performance. Frontiers in Psychology, 6, 1-11. doi: 10.3389/ fpsyg.2015.00984 الس الس الس

Jansen, P., Lange, L., \& Heil, M. (2011). The influence of juggling on mental rotation performance in children. Biomedical Human Kinetics, 3, 223-229. doi: 10.2478/v10101-011-0005-6 الس السلسلس

Jansen, P., Lehmann, J., \& Van Doren, J. (2012). Mental rotation performance in male soccer players. PLoS One, 7, 1310-1315. doi: 10.1371/journal.pone.0048620 الس السلسل

Jola, C., \& Mast, F. (2005). Mental object rotation and egocentric body transformation: Two dissociable processes? Spatial Cognition \& Computation, 5, 217-237. doi: 10.1207/ s15427633scc052\&3_6 1لس

Jolicoeur, P., \& Kosslyn, S. M. (1985). Demand characteristics in image scanning experiments. Journal of Mental Imagery, 9 , 41-49.

Just, M. A., \& Carpenter, P. A. (1985). Cognitive coordinate systems: Accounts of mental rotation and individual differences in spatial ability. Psychological Review, 92, 137-172. doi: 10.1037/0033-295X.92.2.137 سلس

Kail, R., Carter, P., \& Pellegrino, J. (1979). The locus of sex differences in spatial ability. Perception \& Psychophysics, 26, 182-186.

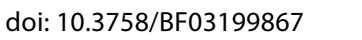

Kaltner, S., \& Jansen, P. (2015). Does body awareness influence visual spatial intelligence? International Journal of Learning, Teaching and Educational Research, 13, 1-13.

Kaltner, S., Riecke, B. E., \& Jansen, P. (2014). Embodied mental rotation: A special link between egocentric transformation and the bodily self. Frontiers in Psychology, 5, 1-11. doi: 10.3389/ fpsyg.2014.00505 السلس

Kanamori, N., \& Yagi, A. (2002). The difference between flipping strategy and spinning strategy in mental rotation. Perception,

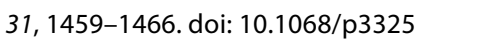

Krüger, J. K., \& Suchan, B. (2016). But you should be the specialist! Weak mental rotation performance in aviation security screeners. Reduced performance level in aviation security with no gender effect. Frontiers in Psychology, 7. doi: 10.3389/fpsyg.2016.00333 سلس الس الس

Liesefeld, H. R., Fu, X., \& Zimmer, H. D. (2015). Fast and careless or careful and slow? Apparent holistic processing in mental rotation is explained by speed-accuracy trade-offs. Journal of Experimental Psychology: Learning, Memory, and Cognition, 41, 1140-1151. doi:10.1037/xIm0000081 السلبلس
Moreau, D. (2012). The role of motor processes in three-dimensional mental rotation: Shaping cognitive processing via sensorimotor experience. Learning and Individual Differences, 22, 354-359. doi: 10.1016/j.lindif.2012.02.003 السلسلسل

Moreau, D. (2013). Constraining movement alters the recruitment of motor processes in mental rotation. Experimental Brain

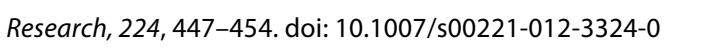

Moreau, D., Clerc, J., Mansy-Dannay, A., \& Guerrien, A. (2011). Spatial ability and motor performance: Assessing mental rotation processes in élite and novice athletes. International Joural

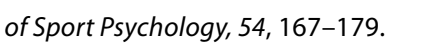

Moreau, D., Clerc, J., Mansy-Dannay, A., \& Guerrien, A. (2012). Enhancing spatial ability through sport practice. Journal of Individual Differences, 33, 83-88. doi: 10.1027/1614-0001/ a000075 سلس

Ozel, S., Larue, J., \& Molinaro, C. (2002). Relation between sport activity and mental rotation: Comparison of three groups of subjects. Perceptual and Motor Skills, 95, 1141-1151. doi: 10.2466/pms.2002.95.3f.1141 الس الس

Parsons, L. M. (1987). Imagined spatial transformation of one's body. Journal of Experimental Psychology: General, 116, 172191. doi: 10.1037/0096-3445.116.2.172 سلسلس

Pietsch, S., \& Jansen, P. (2018). Laterality-specific training improves mental rotation performance in young soccer players. Frontiers in Psychology, 9. doi: 10.3389/fpsyg.2018.00220 سلسلس

Provost, A., Johnson, B., Karayanidis, F., Brown, S. D., \& Heathcote, A. (2013). Two routes to expertise in mental rotation. Cognitive Science, 37, 1321-1342. doi: 10.1111/cogs.12042 سلس سلس

Seya, Y., \& Mori, S. (2015). Tradeoff between manual response speed and pursuit accuracy revealed by a deadline procedure. Experimental Brain Research, 233, 1845-1854. doi: 10.1007/ s00221-015-4256-2 لس

Shepard, R. N., \& Cooper, L. A. (1986). Mental images and their transformations. Cambridge, MA: MIT Press.

Shepard, R. N., \& Metzler, J. (1971, February). Mental rotation of three-dimensional objects abstract. The time required to recognize that two perspective drawings portray. Science, 171, 701-703. doi:10.1126/science.171.3972.701 المالسلسلاس

Steggemann, Y., Engbert, K., \& Weigelt, M. (2011). Selective effects of motor expertise in mental body rotation tasks: comparing object-based and perspective transformations. Brain and Cognition, 76, 97-105. doi: 10.1016/j.bandc.2011.02.013 السالسلسل|

Vereza, S. C. (1999). Philosophy in the flesh: The embodied mind and its challenge to Western thought. Documentação de Estudos em Lingüística Teórica e Aplicada, 17. doi: 10.1590/ S0102-44502001000100008 السلسلم

Voyer, D. (1997). Scoring procedure, performance factors, and magnitude of sex differences in spatial performance. American Journal of Psychology, 110, 259-276. doi: 10.2307/1423717 المالسلسلة

Voyer, D. (2011). Time limits and gender differences on paper-and-pencil tests of mental rotation: a meta-analysis. Psychonomic Bulletin \& Review, 18, 267-277. doi: 10.3758/s13423-010-0042-0 اليسلس 
Voyer, D., \& Bryden, M. (1990). Gender, level of spatial ability, and lateralization of mental rotation. Brain and Cognition, 13, 18-29. doi: 10.1016/0278-2626(90)90037-0 الهلسلسلس

Voyer, D., \& Jansen, P. (2017). Motor expertise and performance in spatial tasks: A meta-analysis. Human Movement Science, 54, 110-124. doi: 10.1016/j.humov.2017.04.004 المالسلس

Wexler, M., Kosslyn, S. M., \& Berthoz, A. (1998). Motor processes in mental rotation. Cognition, 68, 77-94. doi: 10.1016/S00100277(98)00032-8 |سلسل|

Wilson, M. (2002). Six views of embodied cognition. Psychonomic Bulletin \& Review, 9, 625-636. doi: 10.3758/BF03196322 الهالسلسلاس

Wohlschläger, A., \& Wohlschläger, A. (1998). Mental and manual rotation. Journal of Experimental Psychology: Human Perception and Performance, 24, 397-412. doi: 10.1037/00961523.24.2.397 المالسلس
Wright, R., Thompson, W. L., Ganis, G., Newcombe, N. S., \& Kosslyn, S. M. (2008). Training generalized spatial skills. Psychonomic Bulletin \& Review, 15, 763-771. doi: 10.3758/PBR.15.4.763 السلسلسلس Yu, A. B., \& Zacks, J. M. (2015). How are bodies special? Effects of body features on spatial reasoning. The Quarterly Journal of Experimental Psychology, 69, 1210-1226. doi: 10.1080/17470218.2015.1079225 السلسلس

Zhao, B., \& Sala, S. D. (2018). Different representations and strategies in mental rotation. Quarterly Journal of Experimental Psychology, 71, 1574-1583. doi: 10.1080/17470218.2017.1342670 البلسلس 